International Review of Research in Open and Distributed Learning Volume 18, Number 7

November -2017

\title{
Professional Online Presence and Learning Networks: Educating for Ethical Use of Social Media
}

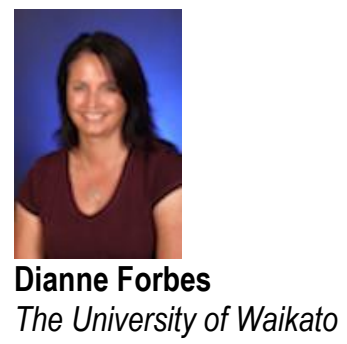

\begin{abstract}
In a teacher education context, this study considers the use of social media for building a professional online presence and learning network. This article provides an overview of uses of social media in teacher education, presents a case study of key processes in relation to professional online presence and learning networks, and highlights issues and challenges for wider consideration. Specific practical illustrations are provided, relating experiences when starting out with social media, integrating coursework challenges for student teachers, and considering feedback and future planning. Social media is used in teacher education for sharing content, discussing, and collaborating. There are challenges and risks with social media in an academic context. Students require differentiated scaffolding depending on their expertise and confidence. In terms of social implications, professionals are warned to safeguard online reputation, while making proactive use of social media to enhance learning networks.
\end{abstract}

Keyword: teacher education, social media, professional online presence, learning networks, open and distributed learning

\section{Introduction}

Recent years have seen increasing use of social media in higher education, with scholarship emerging around the ubiquity of social media as a fast trend (Johnson, Adams Becker, Estrada, \& Freeman, 2014). As in the general population, there is a growing proportion of academics engaging with social media as a regular professional pursuit. The trend is for increasing uptake of tools and platforms like Twitter, Blogging, and other digital media across professional contexts and for teaching purposes (Fox \& Bird, 2017; Lupton, 2014). 
In teacher education, leveraging the power of social media for social learning is increasingly recognized as a key skill for teachers (Johnson et al., 2014). Of course, this is more a set of dispositions, competencies, and literacies than a skill as such, and the complex set of understandings must be underpinned by awareness of ethical and social responsibilities. This paper illuminates some of the finer points regarding leverage of social media for professional learning in teacher education. As teacher educators gradually immerse themselves in the possibilities, teacher education students are also beginning to explore educative potential. For example, a New Zealand study by Wright (2010) explored how Twitter could help teacher education students to develop reflective practices while on teaching practicum placements in schools.

In teacher education, uses of social media include the production and sharing of content, discussion and interaction with content, and collaborative connection with other social media users (Johnson et al., 2014). Each of these uses is briefly discussed in turn.

Firstly, the production and sharing of content occurs where users are encouraged to use social media to both understand and communicate ideas (Gesser, 2013), promoting openness by making research and resources available outside of the academy (Chayko, 2014; Lupton, 2014; McCarty, 2011). It is rare now to attend a conference in teacher education without a corresponding Twitter hashtag and a series of interest groups emerging. In a similar vein, social media can function as a "backchannel" for communication within or between classes, so that students and teachers continue to share alongside formal channels (Greenhow \& Gleason, 2012).

Secondly, discussion and interaction with content can be asynchronous or in real time, enabling collective thinking (Johnson et al., 2014), engagement in social commentary (Lupton, 2014), and ultimately knowledge construction via networking (Selwyn, 2011). As such, learning through social media is underpinned by a sociocultural conceptualization whereby interaction and development of new understandings are inextricably linked and contextualized (Vygotsky, 1978). Individual and collective transformations of knowledge occur through dialogic exchanges between people (Delahunty, Verenikina, \& Jones, 2013; Vygotsky, 1978).

Thirdly, collaborative connections with other users are possible as social media can enable collaboration across institutions and with field experts (Johnson et al., 2014). The potential for collective work is widened due to the public nature of many networks, creating opportunities to interact with and learn from individuals who may not easily meet in person (Couros \& Jarrett, 2012). Importantly, networks enable questions to be promptly answered (Richardson \& Mancabelli, 2011). For some, social media is about building relationships (Greenhow \& Gleason, 2012; McCarty, 2011; Nolan, 2013), giving and receiving support (Lupton, 2014), and mitigating feelings of isolation (Wright, 2010). For many, social networks constitute personal/professional learning environments and communities of practice (Lim, Agostinho, Harper, \& Chicaro, 2014).

Conceptually, the use of social media also can be understood as a shift to connectivist learning (Siemens, 2005), prompted by creation of new knowledge, the primacy of connection, and the growth in the 
abundance and complexity of knowledge (Siemens, 2009). Connectivism emphasises the ways learning is distributed in a network, acknowledging the diversity of networks and the strengths of ties, as well as ongoing rapid change (Siemens, 2005, 2009).

In these ways, social media can be employed as a backchannel, an ongoing discussion and a personal learning network. Overall, social media can enable teacher education participants to be "connected, collective and creative," as Selwyn (2011, p.2) suggests. However, as is always the case with digital technologies, the affordances are not necessarily realized and learning is by no means guaranteed. After all, not all uses of social media are educational or of sufficient quality to contribute to knowledge building. Furthermore, not all uses of social media are ethical or socially responsible. Risky, inappropriate, damaging, and even illegal episodes on social media have led to promotion of "eprofessionalism," particularly in fields like health sciences (Chester, Kienhuis, Pisani, Shahwan-Akl, \& White, 2013). This is a reminder to members of professional groups, including graduates joining professions, to be mindful of the need to take great care with the use of social media in order to safeguard their own credibility, and the confidentiality of clients.

In academic and professional contexts, stumbling blocks and issues with social media include the time consuming nature of establishing and maintaining social media contacts (Lupton, 2014; Richardson \& Mancabelli, 2011). For many educators, there are concerns about separating public and private life, and a wish to preserve privacy (Lupton, 2014; Johnson et al., 2014; Fox \& Bird, 2017). Similarly, there is uncertainty about the boundaries between personal and professional use of social media (Chester et al., 2013; Lupton, 2014), which can easily become indistinct (Fox \& Bird, 2017). Academics are troubled by issues around online safety and security (Johnson et al., 2014), including fear of becoming a target of attack (Lupton, 2014). A complex set of concerns revolve around integrity in terms of the risk of offending one's audience, while academics may also be at pains to be taken seriously by colleagues who might regard social media as inappropriate or trivial (Lupton, 2014). There is also a fear of losing control over intellectual property. These uncertainties and fears are exacerbated in many cases by a lack of clear policy structures around the use of social media in academic and professional contexts (Chester et al., 2013; Johnson et al., 2014). As a result, teacher educators and students alike can be reluctant to use social media for educational purposes, and may confine their use to private and recreational functions (Selwyn, 2011). While resistance may be due to a lack of awareness of the educative affordances of social media, it can also be a deliberate choice in order to avoid the pitfalls mentioned, and it cannot be assumed that students or staff will necessarily extend their use of social media in ways that are supportive of learning and teaching. In order to do so, tertiary students, academic staff, and emerging professionals need to develop an awareness of how to harness the affordances of social media in ethical and socially responsible ways, proactively safeguarding against the very real dangers, and challenging outdated notions to fully understand the new opportunities, alongside the new risks and complexities (Osborne \& Connelly, 2015; Fox \& Bird, 2017).

Ethical use of social media means adhering to professional standards, even outside of work contexts. Since social media involves public expression, standards apply regardless of whether an individual is 
working at the time of posting. Key ethical principles to apply to the use of social media include confidentiality, a professional expectation of those who work with clients and who owe loyalty to companies and institutions. A related principle is the obligation of responsible care, where professionalism entails doing good and minimizing harm. This in turn is relate to justice, in terms of fairness, and respect for human rights. Breaches of these ethical principles could be regarded as breaches of a professional's moral commitment to clients, society, and the profession. Hence, socially responsible use is a reminder that what an individual does with social media does not occur in a vacuum and is likely to affect or influence others by virtue of the social character of the communications. Fundamentally, there is an expectation that professionals will apply sound judgment to all communications and dealings, on and off social media (O’Neill, 2015). Of course this is far from being a clear-cut matter, hence the need for clarification of policy, codification of principles for ethical decision-making, and ongoing discussions and development among representative professional bodies and those responsible for educating professionals.

Looking to the future, there are implications for student learning, professional expectations, policy, research, and practice in teacher education. Social media mirrors real-life learning, now and in the future. It is essential that students learn to manage social media processes for the sake of lifelong learning, since "Students will need to participate in these learning networks to stay on top of their fields of interest and to advance their careers" (Richardson \& Mancabelli, 2011, p. 135). For these reasons, educators need to lead by modeling transparency, network literacy, sharing, and participation, underpinned by ethical and social responsibility. Increasingly, these functions are a professional expectation across every discipline and field of expertise (Chester et al., 2013; Nolan, 2013; Osborne \& Connelly, 2015).

Professionals in the twenty-first century use social media to promote their professional selves (Fox \& Bird, 2017), and to network in pursuit of lifelong learning and professional development (Greener, 2015). It therefore stands to reason that professional preparation should incorporate use of social media for professional online presence and learning networks. Such preparation needs to go beyond the reactive limitations of early eprofessional notions of protecting oneself by using a pseudonym online (Tunick, Mednick, \& Conroy, 2011). Rather than avoiding or hiding one's identity online, a more proactive approach is to cultivate and promote a professional online persona (Barbour \& Marshall, 2012).

To further research, Greenhow and Gleason (2012) highlight the importance of looking at participant perspectives on social media experiences, and call for studies of teachers' purposes for social media integration. Davis, Deil-Amen, Rios-Aguilar and González Canché (2012) suggest there is a need to look at less traditional students, distance students, and those who are older and more isolated from campus community. Further research in the Asia-Pacific region is also needed (Lim et al., 2014).

Finally, in terms of practice, this paper contends that teacher educators have a professional responsibility to challenge teachers to adapt and optimize the learning opportunities afforded by social media.

\section{POPLN: Professional Online Presence and Learning Networks}


Fundamentally, a key premise of this paper is that teacher educators must look to make professional use of social media, before turning their attention to social media for student learning. In essence, this paper highlights two aspects of social media in teacher education: Professional Online Presence and Learning Networks.

The first element, Professional Online Presence, involves cultivation of a social media profile and footprint that is in keeping with one's goals as an educator. This involves ethical behaviour and formation of a professional identity, in the sense of presenting self, described by Goffman (1959). For example, in relation to social media behaviour, it is vital that educators are mindful of netiquette and "visible in positive ways" (Nussbaum-Beach \& Hall, 2012, p.89), carefully managing online reputation. In terms of teaching practice, social media is an avenue for continuing and expanding beyond the walls of the classroom or Learning Management System (Gesser, 2013). In this day and age, "Connected educators google well" (Nussbaum-Beach \& Hall, 2012, p.88), and it is readily apparent which professionals have harnessed the power of social media for teaching and learning. Professional online presence is after all, a deliberate stance, and one that is ethically and intelligently cultivated in the service of educational endeavour.

Secondly, Learning Networks are an opportunity to join and sustain a community of professionals, to engage in adaptive help seeking and to adopt a proactive stance in relation to professional learning. Social media affords educators the opportunity to regularly "trade information, share resources, ask and answer questions, and debate and discuss educational issues of the day" (Couros \& Jarrett, 2012, p. 149).

Educators and students alike engage in adaptive help seeking when they know how and when to seek information, feedback, support, and assistance, and turn to their networks as part of a cycle of selfregulated learning (Newman, 2002; Steed \& Poskitt, 2010). Via connected learning communities, educators and students can become "do-it-yourself" learners, selecting mentors and orchestrating their own learning (Nussbaum-Beach \& Hall, 2012, p.11). Teachers need to take control of professional learning, looking beyond pre-packaged courses provided by others. It is often said that effective teachers must be learners, and it stands to reason that effective learners are self-directed and entrusted with choices and control over personalized programmes of learning. Effective teachers and learners must have an open mindset and be prepared to learn in new environments.

\section{A Case Study: Key Experiences and Discoveries}

The University of Waikato in New Zealand offers several blended teacher education programmes in New Zealand, including a ground-breaking and award winning undergraduate Mixed Media Programme (MMP); a graduate Masters of Teaching and Learning (MTL) degree; and a refresher course for inservice teachers (TRC). Across these programmes student/teachers are encouraged to extend their use of social media for professional purposes. Starting with Twitter, and branching out to Facebook, Pinterest, Blogs, and ePortfolios, students have connected and reflected, meeting in real time, sharing and reviewing 
resources, tracking news, and engaging with the wider profession. This paper documents some of the processes involved and feedback received, as well as ideas for the future. Documentation of these processes, in an ethnographic sense, is likely to be useful to tertiary and teacher educators starting out with social media, as there are few written accounts of how lecturers appropriate social technologies for learning activities (Hamid, Waycott, Kurnia, \& Chang, 2014; Lim et al., 2014). In what follows, data was generated via journaling of the processes throughout the period of study (2013-2015). Students contributed via voluntary forum posts, anonymous feedback, and assigned reflective work. All quotes are used with student permission.

\section{Starting Out With Professional Use of Social Media}

In 2013, the first steps invited student-teachers to take part in a social media challenge involving establishment of a professional social-networking presence, via Twitter.

Teacher education students established Twitter accounts, started following teachers and educational authorities, and joined communities of professionals to discuss educational issues (e.g., \#edchatnz, @TeachHub). Students often lurked in Twitter, following and reading, before gradually beginning to retweet and to post links to teaching resources. The most confident students seemed to be influenced at an early stage by a particular hashtag, group or individual. For example, one student discussed the social media challenge in person with his school leader and was inspired to follow the senior colleague and to build his network from that point. Twitter was a popular choice, branching out from Facebook which was generally already a social favourite for the students. A few tentatively established blogs, struggling with uncertainty about "what to blog" but gradually finding their voices. Some established eportfolios and shared these for feedback. Students critiqued the usability of the social media tools and exchanged advice on how to overcome hurdles relating to confidence and technicalities (who to follow, what to post, how to add a tab to the eportfolio). As the semester progressed, students persevered and followed a wider range of international educators, read more widely in the blogosphere, and independently located then shared online resources like tutorials. Pinterest and Scoopit entered the range of possibilities. A class hashtag was established. Those who identified a specialist interest to blog about were able to sustain their blogging adventures.

Student feedback from the class of 2013 indicated a wish to formalize the social media challenge in some way, via summative assessment for course credit, and closer integration with the assigned work in the course. Students valued the activity but found it time consuming, and wanted license to spend more study time on the social media challenge.

\section{POPLN 2014}

In response to the success of the social media challenge in 2013 and student feedback and suggestions relating to the development of the task, a more comprehensive approach was trialed in 2014, entitled Professional Online Presence and Learning Networks or the POPLN challenge. 
To initiate POPLN, students were assigned background reading about professional uses of social media in education. These included media reports highlighting the dangers of social media for teachers who have faced disciplinary action for transgressions; the aforementioned guidelines from the teachers' union and regulatory bodies and a range of examples of social media tools along with explanatory YouTube clips, tutorials, and professional users in education.

Students were prompted to consider the following:

- Cybersafety: Your online identity and how to safeguard your professional reputation, integrity, and privacy;

- Being proactive: Establishing a professional online presence;

- Lifelong learning: Using the Internet to build a personal/professional learning network; and

- Challenges: Expanding your repertoire of social networking tools for professional purposes.

With these considerations and goals in mind, the essence of the POPLN challenge directed students to:

Select a tool to begin with, any free online social networking tool will do.

- find the tool online,

- $\quad$ establish a profile,

- explore the uses for professional networking and learning,

- find out how others use it,

- reflect on the potential for future learning and help seeking,

- share some of your thoughts in our Moodle forum, and

- respond to peers in our Moodle forum.

In response to students' preference for the task to be more integral to the assigned work, the 2014 class were required to write a proposal and interim progress report within the first month of semester, outlining choice of tool/s and intentions in cultivating a professional online presence and learning network. Students were encouraged to share postings, quoting evidence of their own social media presence, and self-evaluating their learning to date. Mid-course, students were required to participate in a forum in which they shared a learning experience connected with the POPLN challenge, and exchanged advice on how to optimise the learning potential of the available social media tools. 
At the end of semester, students were required to produce a final report, reflecting on their journey with POPLN and use of social media tools, and incorporating critical analysis of the affordances and limitations of their chosen tool for learning and professional networking. At this stage, students were also prompted to set goals for ongoing professional learning through social media. Alongside these assigned coursework elements, an optional asynchronous forum remained open for the duration of the semester so that students could discuss POPLN progress, issues, share developments, and ask questions. In addition, a class hashtag was again established, but this time a Twitter widget was embedded in the Moodle course to enable students to track the class tweets within the course.

Throughout the POPLN challenge, students used the progress forum to pose questions, share links, and signal their own presence (e.g., by posting their Twitter handles or links to new blog posts). Students exchanged feedback, commenting on each other's efforts and reports of progress, and encouraging their peers. Common challenges articulated by the students during the challenge included feeling exposed and vulnerable at the start, so that the first tweet was a hurdle. Moving beyond lurking in Twitter took the students through a progression that typically involved retweeting before posting original links and commentary. After taking the first steps, the next challenge involved maintaining momentum and sustaining purposeful patterns of contribution. Learning to use hashtags was cited as a challenge for some students, along with the struggle to become familiar with strange terminology like "handle" (Twitter) and "pins" (Pinterest). A common concern was dealing with overload, due to the vast array of social media options and the volume of postings, pins, and tweets involved. Some of the students reported overload stemming from managing multiple social media accounts. In the realm of professional blogging, copyright became a concern for one student who wanted to use images from a children's book on her blog. This initiated an authentic inquiry for the student involved, as she looked into the protocols, identified the copyright holder, and negotiated permissions. Another key breakthrough in learning terms came as students became discerning about who to follow, and importantly determined who NOT to follow on social media, in terms of corporate entities and individual commentators who detracted from the professional focus of learning as a student teacher. Overall, students said they liked the open-ended style of POPLN and the choice involved in the design of the challenge, selecting their own tools and setting their own goals for social media use. In particular, students reported enjoyment in connecting with each other and with a wider "community of practice."

As Cameron reflected,

The main benefit for me has been extending my community of practice beyond the colleagues of my own school. To be able to follow and communicate with teachers and educational organizations with similar class levels, curriculum foci, interests and concerns enriches and supports one's own practice, but there is also an array of new initiatives, perspectives and research that I might never have known about in my very familiar and comfortable small town, small school bubble. I look forward to continuing to build my connections through the rest of my study and back into the classroom.

\section{5: Feedback and Future Planning}


Subsequent to the 2014 POPLN challenge, extending the use of Twitter to provide a hashtag for each class, and engaging in synchronous 'tweetmeets' with new classes to discuss coursework, students have experimented with Tweetchat and Storify to collate and manage coursework related conversations. New cohorts of students have engaged and responded to the POPLN challenge, and have diversified to experiment further with visual tools like Pinterest. As Angela reflected in relation to Pinterest,

It has been a great tool to collect resources related to teaching. For example, I have been interested in modern learning environments so using Pinterest, I was able to find images that helped me gain an understanding and insight to what this might look like.

In the meantime, students' use of Twitter evolved and became more sophisticated, as articulated by Josie, who discerned several dimensions to her use of the tool,

Twitter has opened up professional learning possibilities in many ways. Firstly, through 'following' specific education-based individuals as well as organizations, I have been able to stay updated regarding movements relating to educational policy and research through the comments or 'posts' others have made through Twitter. I have also found this medium useful with regard to resources. There are many organizations that actively use Twitter to share their great ideas for classroom activities, and positive experiences they have had using particular resources. CORE Education and the Science Learning Hub are examples of some Twitter users who post tips for their followers to use. Another dimension of awareness I have encountered through the use of social media is the ability, when actively looking, to stay updated about the latest and greatest in terms of educational opportunities. There have been summits, conferences and professional learning sessions that have been 'tweeted' about, and I have come to know about these events solely through reading Twitter. I have visited many websites and blog pages as a direct result of tweets that I have read. Being connected in this way has brought me to academic readings, topical debates and page after page of classroom activity sites.

Students still reported that their biggest challenge was finding the confidence to post. Surmounting this hurdle was also the most significant breakthrough, and with it came the realisation of the power of social media for collaboration and discovery.

As Angela related,

My breakthrough moment would definitely have to be joining the "What is School" educational chat. I was able to connect with educators from around the world for one hour to discuss educational technology. It was a great experience that allowed me to gain insight on the perspectives of other educators and discuss issues and strategies with using technology in the classroom.

For example, during the "what is school" chat one person stated that, "Closed minds are the biggest roadblock. Just seeing tech and not the possibilities" (Drager, 2014) and in regards to strategies, Lang (2014) shared, "Technology should be used as a transformational tool for innovation and creativity, not an 
add-on." A common theme was that technology should be used to enhance collaboration, discovery, and a sense of empowerment.

Empowerment is similarly a feature of the student feedback arising from the social media challenge, indicating that students have valued the opportunity to explore and to increase awareness of social media affordances for learning. Some students have struggled with the open-ended and unstructured design of the social media challenge, despite checkpoints and advice, expressing a need for firmer guidance in relation to learning steps and a more explicit scaffold. For example, Anne confided that she was "suffering from information overload", and needed to shift her strategy from "trawling around ... to be more purposeful and focus on assignment needs. I am following twitter, Pinterest and Linkedin (and links from fellow students) but not yet contributing anything really significant."

Anne's experience was shared by a significant proportion of students in the class, and suggested a need for stepping students through a clearer progression of mini-challenges, at least in the initial stages of the POPLN challenge. For example, a clear goal each week - to move students beyond trawling and following, and onto creation of content and purposeful collaboration. Overall, $25 \%$ of the class admitted to struggling at some point in the POPLN challenge, and echoed Anne's experiences above. The students' concerns revolved around two areas:

1. Understanding the purpose of social media use as a professional, as distinct from personal use, and how to focus this use by knowing where to start and how to narrow down the overwhelming range of options.

2. Time management - managing distraction and remembering to make time for a self paced task.

In essence, both of these challenging areas can be summed up as Focus. Students need help to focus the purpose of their social media use, and to focus their use of time.

The challenge for teachers is to differentiate the scaffolding for students, to provide clear, focused goals and boundaries for those who need a tighter structure, while promoting experimentation and innovation by advanced users.

In some cases, students reported an about-turn in their thinking about social media, admitting to previously dismissing the likes of Twitter as trivial and of no significance for learning purposes. For example, Nathan commented,

My thinking has completely changed as far as social media goes. Before doing this paper my thoughts about twitter were that it was a tool that enabled people to blurt out their thoughts to the world. Now I see it as a platform for social interaction, sharing, and learning.

Throughout 2015 and 2016, students have continued to use Twitter in particular for sharing resources and ideas of wider interest to colleagues, and for seeking help with study-related issues. Prioritising Twitter has been a way to focus student efforts on one tool to start with, with Twitter the tool of choice due to the 
way it lends itself to following professionals and separating personal/professional use (Fox \& Bird, 2017). Wider experimentation with synchronous tweetchats across the profession has occurred, with students joining in and reporting to others. In a similar vein, national professional groups within Facebook have become popular, enabling students to virtually join the profession prior to graduation. In order to extend these conversations, an alumni hashtag has been established to promote and collate ongoing interactions with new professionals.

Reflecting on the use of social media in the past four years gives rise to three particular intentions for the year ahead:

Firstly, it is apparent that a degree of differential scaffolding is needed for students, to support those who are at different stages in their experience and comfort with social media. With this in mind, a tiered approach to tasks is proposed (Table 1) in order to balance the desire for structure for those who need it, alongside the successful open-ended character of the challenge overall.

Table 1

Structuring Challenges to Suit Level of Expertise

Level of expertise:

\begin{tabular}{|l|l|}
\hline Beginners & $\begin{array}{l}\text { First tweets, establish core following, begin } \\
\text { to reflect on impact and potential. }\end{array}$ \\
\hline Intermediate & $\begin{array}{l}\text { Expanding contributions, gaining } \\
\text { followers, joining synchronous tweetchats. }\end{array}$ \\
\hline Advanced & $\begin{array}{l}\text { Diversifying platforms, hosting a tweetchat, } \\
\text { blogging guidelines for others to promote } \\
\text { professional learning through social media. }\end{array}$ \\
\hline
\end{tabular}

Secondly, it is intended that further concrete evidence of student learning through social media will be generated, via entry and exit surveys of students prior to commencing the POPLN challenge and at the end of semester. Students will be asked to provide evidence of social media use and demonstrable learning outcomes stemming from the use of social media tools and processes.

Finally, as mentioned, the longitudinal impact of social media will be investigated by arranging to monitor a group of students after graduation. This will enable exploration of whether and how emerging professionals continue to use social media for learning, and the factors that lead to this continuity. 
While the experimentation with social media for professional learning is only beginning, there have been substantial benefits noted, alongside several issues and challenges to acknowledge.

\section{Issues and Challenges}

Considering the aforementioned experiences, there are a number of emergent issues and challenges, briefly summarized next.

\section{Skepticism and Dismissal}

Teacher education encourages critical thinking, questioning, and reflective practice. However, when faced with social media, educators sometimes respond with the kind of cynicism that detracts from openmindedness (Greener, 2015). This reflects the lack of credibility cited as a concern by Lupton's (2014) academics. Furthermore, as Selwyn (2011) suggests, not all students will readily leap at the chance to use social media in an educational and professional context.

Professional commentary and the track record explored with students is persuasive. There remains, nevertheless, a need to generate data on the effects of POPLN after students graduate as teachers and to that end, a longitudinal study is planned to follow up the cohorts of 2013-2016 to ascertain whether and how they continue professional learning through social media. Having used social media for learning during one's degree, do graduates continue to harness social media for ongoing professional learning? How are learning networks cultivated and expanded?

\section{Teachers as Learners}

Teachers (including student teachers) are often looking for ideas that are directly applicable to their own classrooms and students - they want immediate practical application. Sometimes, teachers leap ahead to try things out with students before they have invested in their own professional learning. It has been a challenge to have teachers take a step back and to put their own learning first. For example, after an initial introduction to POPLN, student teachers have asked, "how can I implement this as a primary teacher?" and "I can't wait to use social media with my students but how will the school react?"

Student teachers are cautioned not to rush to use social media with students, but instead to take time to try out the tools and social media environment, for professional learning, in order to become more familiar with the risks and possibilities. This is not to suggest that POPLN is irrelevant to the classroom, since after all, teachers as learners will gain many ideas via social media that can and do have immediate classroom application. At the same time, professional learning through social media enables insight into issues of ethics, privacy, copyright, netiquette, time management, and digital literacy, all of which inform teaching practice.

\section{Safety, Privacy, and Integrity}


There are so many horror stories about mismanagement of online identity and loss of professional integrity due to over sharing. A professor recently remarked that it is safer to stay away from the Internet as far as possible, to keep a low profile, and avoid creating a digital footprint.

In this day and age, avoidance of a digital footprint is unrealistic, as anyone who "Googles" themself will learn. It is dangerous to leave management of one's online identity to chance, or to other people (Barbour \& Marshall, 2012; Osborne \& Connelly, 2015). Rather, as fully functioning citizens, it is the responsibility of each individual to proactively protect and project online identities that are in keeping with our best selves. This is not a simple matter of image management, in a shallow form, but rather a plea to use the Internet in ways that are safe, protective of privacy and human rights, ethically astute, critical, discerning (Brookfield, 2015), and in keeping with one's professional roles and social responsibilities (Fox \& Bird, 2017).

\section{Future Research}

A cross-disciplinary approach to future research could involve case studies of social media from diverse faculties and institutions, to extend the study to multiple case studies.

In terms of practice, this might extend to encouraging students to incorporate social media within assignments across courses, as a means of data collection, research and writing assistance, collegial discussion, and dissemination of work.

In conclusion, this paper has chronicled some of the University of Waikato's experiences with social media in teacher education during recent years, focusing on the establishment of a professional online presence and learning network. This paper has suggested practical approaches to integrating social media teacher education as a series of coursework tasks. While there are challenges related to attitudes, learning dispositions, and safety risks, the highlights are significant. Not least among these is the importance of disrupting assumptions, opening minds, and raising awareness of new possibilities with social media in teacher education and across tertiary disciplines. Developing critical, discerning and learning-oriented uses of social media is a crucial part of preparing emerging professionals for ongoing networking in ethical and socially responsible ways.

\section{References}

Barbour, K., \& Marshall, D. (2012). The academic online: Constructing persona through the World Wide Web, First Monday, 17(9). Retrieved from http://firstmonday.org/ojs/index.php/fm/article/view/3969/3292 
Brookfield, S. (2015). Teaching students to think critically about social media, New Directions for Teaching and Learning, 144, 47-65.

Chayko, M. (2014). Techno-social life: The Internet, digital technology, and social connectedness, Sociology Compass, 8(7), 976-991.

Chester, A., Kienhuis, M., Pisani, H., Shahwan-Akl, L., \& White, K. (2013). Professionalism in student online social networking: The role of educators, E-Learning and Digital Media, 10(1), 30-39.

Couros, A., \& Jarett, K. (2012). Twitter. In S. McLeod, \& C. Lehmann (Eds.). What school leaders need to know about digital technologies and social media (pp. 147-152). San Francisco, CA: Jossey Bass.

Davis III, C.H.F., Deil-Amen, R., Rios-Aguilar, C., \& González Canché, M.S. (2012). Social media and higher education: A literature review and research directions. Report printed by the University of Arizona and Claremont Graduate University. Retrieved from https://works.bepress.com/hfdavis/2/

Delahunty, J., Verenikina, I., \& Jones, P. (2013). Socio-emotional connections: Identity, belonging and learning in online interactions. A literature review, Teaching, Pedagogy and Education, 23(2), 243-265.

Fox, A., \& Bird, T. (2017). The challenge to professionals of using social media: Teachers in England negotiating personal-professional identities. Education and Information Technologies, 22(2), 647-675.

Gesser, C.M. (2013). Using social media in the classroom: A community college perspective, American Sociological Association Footnotes, 41(1). Retrieved from http://www.asanet.org/footnotes/jan13/social_media_0113.html \&

Goffman, E. (1959). The presentation of the self in everyday life. London: Penguin.

Greener, S. (2015). Introduction to leading issues in social media for learning. In S. Greener, \& A. Rospigliosi (Eds.). Leading issues in social media research for researchers, teachers and students (pp. 87-88). Reading, UK: Academic Conferences and Publishing International Limited.

Greenhow, C., \& Gleason, B. (2012). Twitteracy: Tweeting as a new literacy practice. The Educational Forum, 76(4), 464-478.

Hamid, S., Waycott, J., Kurnia, S., \& Chang, S. (2014). An empirical study of lecturers' appropriation of social technologies for higher education, Australasian Journal of Educational Technology, 3o(3), 295-311.

Johnson, L., Adams Becker, S., Estrada, V., \& Freeman, A. (2014). NMC horizon report: 2014 Higher 
Education Edition. Austin, Texas: The New Media Consortium.

Lim, J.S.Y., Agostinho, S., Harper, B., \& Chicharo, J. (2014).The engagement of social media technologies by undergraduate informatics students for academic purpose in Malaysia, Journal of Information, Communication and Ethics in Society, 12(3), 177 - 194.

Lupton, D. (2014). 'Feeling better connected': Academics' use of social media. Canberra: News \& Media Research Centre, University of Canberra, Australia.

McCarty, S. (2011). Social media to motivate language learners from before admission to after graduation. In W. Chan, K. Chin, M. Nagami, \& T. Suthiwan (Eds.), Media in foreign language teaching and learning (pp. 87-106). Berlin, Boston: De Gruyter Mouton. Retrieved from https://www.degruyter.com/viewbooktoc/product/1796.54

Newman, R. S. (2002). What do I need to do to succeed... when I don't understand what I'm doing!? Developmental influences on students' adaptive help seeking. In A. Wigfield \& J. Eccles, (Eds.). Development of achievement motivation (pp. 285-306). San Diego, CA: Academic Press.

Nolan, J.M. (2013). In higher education social media is your job, Huffington Post. Retrieved from http://www.huffingtonpost.com/dr-james-michael-nolan/in-higher-educationsocia b $3932373 . h t m l$

Nussbaum-Beach, S., \& Hall, L.R. (2012). The connected educator: Learning and leading in a digital age. Bloomington, IN: Solution Tree Press.

Osborne, N., \& Connelly, L. (2015). Managing your digital footprint: Possible implications for teaching and learning. In A. Mesquita \& P. Peres (Eds.). Proceedings of the $2^{\text {nd }}$ European Conference on Social Media ECSM 2015 (pp. 354-361). Porto, Portugal.

O’Neill, J. (2015). Teachers and ethics. In D. Fraser \& M. Hill (Eds.). The professional practice of teaching in New Zealand (pp. 261-278). Melbourne, Vic.: Cengage.

Richardson, W., \& Mancabelli, R. (2011). Personal learning networks: Using the power of connections to transform education. Bloomington, IN.: Solution Tree Press.

Selwyn, N. (2011). Social media in higher education. The Europa World of Learning. Retrieved from www.worldoflearning.com

Siemens, G. (2005). Connectivism: A learning theory for the digital age. International Journal of Instructional Technology and Distance Learning, 2(1), 3-10.

Siemens, G. (2009), What is connectivism? Retrieved from https://docs.google.com/document/d/14pKVPo_ILdPty6MGMJW8eQVE 
Y1zibZoRpQ2CocePIgc/preview

Steed, C., \& Poskitt, J. (2010). Adaptive help seeking: A strategy of self-regulated learners and an opportunity for interactive formative assessment, Assessment Matters, 2. Retrieved from http://www.nzcer.org.nz.ezproxy.waikato.ac.nz/nzcerpress/assessmentmatters/articles/adaptive-help-seeking-strategy-self-regulated-learners-and-op

Tunick, R.A., Mednick, L., \& Conroy, C. (2011). A snapshot of child psychologists' social media activity: Professional and ethical practice implications and recommendations. Professional Psychology: Research and Practice, 42(6), 440-447.

Vygotsky, L. (1978). Mind in society: The development of higher psychological processes. Cambridge, MA: Harvard University Press.

Wright, N. (2010). Twittering in teacher education: Reflecting on practicum experiences. Open Learning: The Journal of Open and Distance Learning, 25(3), 259-265.

\section{Athabasca \\ University}

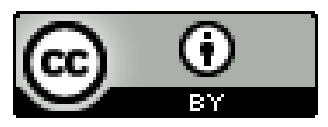

